\title{
Serotonergic Modulation of Plasticity of the Auditory Cortex Elicited by Fear Conditioning
}

\author{
Weiqing Ji and Nobuo Suga \\ Department of Biology, Washington University, St. Louis, Missouri 63130
}

In the awake big brown bat, 30 min auditory fear conditioning elicits conditioned heart rate decrease and long-term best frequency (BF) shifts of cortical auditory neurons toward the frequency of the conditioned tone; 15 min conditioning elicits subthreshold cortical BF shifts that can be augmented by acetylcholine. The fear conditioning causes stress and an increase in the cortical serotonin (5-HT) level. Serotonergic neurons in the raphe nuclei associated with stress and fear project to the cerebral cortex and cholinergic basal forebrain. Recently, it has been shown that $5-\mathrm{HT}_{2 \mathrm{~A}}$ receptors are mostly expressed on pyramidal neurons and their activation improves learning and memory. We applied 5-HT, an agonist ( $\alpha$-methyl-5-HT), or an antagonist (ritanserin) of 5- $\mathrm{HT}_{2 \mathrm{~A}}$ receptors to the primary auditory cortex and discovered the following drug effects: (1) 5-HT had no effect on the conditioned heart rate change, although it reduced the auditory responses; (2) 4 mм 5-HT augmented the subthreshold BF shifts, whereas $20 \mathrm{~mm}$ 5-HT did not; (3) $20 \mathrm{~mm}$ 5-HT reduced the long-term BF shifts and changed them into short-term; (4) $\alpha$-methyl-5-HT increased the auditory responses and augmented the subthreshold BF shifts as well as the long-term BF shifts; (5) in contrast, ritanserin reduced the auditory responses and reversed the direction of the BF shifts. Our data indicate that the BF shift can be modulated by serotonergic neurons that augment or reduce the BF shift or even reverse the direction of the BF shift. Therefore, not only the cholinergic system, but also the serotonergic system, plays an important role in cortical plasticity according to behavioral demands.

Key words: bat; best frequency; neuromodulatory systems; reorganization; stress; tonotopic map

\section{Introduction}

The frequency (cochleotopic) map in the primary auditory cortex (AI) can be modified by auditory experiences including learning and injury (Irvine and Rajan, 1996; Ohl and Scheich, 2005). In the AI of the big brown bat, a long-term "centripetal" best frequency (BF) shift [i.e., the shift toward the frequency of a conditioned tonal stimulus (CS)] is elicited by $30 \mathrm{~min}$ auditory fear conditioning (Gao and Suga, 2000). The CS activates the neural circuits of the AI and the corticofugal system to elicit a small short-term BF shift. In the meantime, the paired CS and unconditioned stimulus (US) indirectly increase cortical acetylcholine (ACh) release from the cholinergic basal forebrain and make the BF shift large and long term. This process is modulated by several neuromodulators (Suga and Ma, 2003). The importance of ACh in the BF shift has been well demonstrated (Ji et al., 2001; Ji and Suga, 2003). However, serotonergic modulation of BF shifts has not yet been studied.

The mammalian neocortex has an extensive serotonergic input from the raphe nuclei (Jacobs and Azmitia, 1992; Barnes and Sharp, 1999). Exogenously applied 5-hydroxytryptamine (serotonin or 5-HT) excites GABAergic neurons or suppresses the

Received Dec. 20, 2006; revised March 29, 2007; accepted April 2, 2007.

This work was supported by the National Institute on Deafness and Other Communicative Disorders Grant DC000175. We thankS. E. Miller for editing our current manuscript.

Correspondence should be addressed to Nobuo Suga, Department of Biology, Washington University, One Brookings Drive, St. Louis, M0 63130. E-mail: suga@biology.wustl.edu.

D01:10.1523/JNEUROSCI.5528-06.2007

Copyright $\odot 2007$ Society for Neuroscience $\quad$ 0270-6474/07/274910-09\$15.00/0 responses to sensory stimuli of the inferior colliculus (Hurley et al., 2002), lateral amygdala (Stutzmann and LeDoux, 1999), and somatosensory cortex (Waterhouse et al., 1986). Of the 14 subtypes (seven families) of 5-HT receptors (Barnes and Sharp, 1999), cortical 5- $\mathrm{HT}_{2 \mathrm{~A}}$ receptors are mostly located on the pyramidal neurons (Liang et al., 1998; Jakab and Goldman-Rakic, 2000) and mediate the depolarization of layer V pyramidal neurons (Araneda and Andrade, 1991; Zhou and Hablitz, 1999; Lambe et al., 2000; Marek et al., 2001), whereas cortical 5- $\mathrm{HT}_{3}$ receptors are exclusively located on the GABAergic neurons (Barnes et al., 1989; DeFelipe et al., 1991; Roerig and Katz, 1997; Puig et al., 2004) and mainly mediate 5-HT-induced inhibition. Importantly, $5-\mathrm{HT}_{2 \mathrm{~A}}$ receptors increase the release of cortical ACh (Quirion et al., 1985; Nair and Gudelsky, 2004) and glutamate (Aghajanian and Marek, 2000; Hasuo et al., 2002; Chen et al., 2003), whereas $5-\mathrm{HT}_{3}$ receptors decrease ACh release in the cortex (Maura et al., 1992; Crespi et al., 1997; Giovannini et al., 1998).

Serotonergic neurons play a role in reconfiguring neural circuitry in the sensory and motor systems and are associated with anxiety and defensive behaviors (Eison and Eison, 1994; Meneses, 1999). Recently, it has been shown that $5-\mathrm{HT}_{2 \mathrm{~A}}$ receptors alone mediate fear and anxiety states (Castilho and Brandao, 2001; Weisstaub et al., 2006) and that activation of 5- $\mathrm{HT}_{2 \mathrm{~A}}$ receptors improves learning and working memory (Williams et al., 2002; Harvey, 2003; Harvey et al., 2004; Romano et al., 2006). Also, 5-HT is involved in the control of both cardiovascular and acute psychological stress reactivity (Davies et al., 2006). We hy- 
pothesized that the conditioning-elicited cortical plasticity could be related to stress and be modulated by $5-\mathrm{HT}$. Thus, we investigated the effects of low and high doses of 5-HT as well as an agonist and antagonist of $5-\mathrm{HT}_{2 \mathrm{~A}}$ receptors on the cortical $\mathrm{BF}$ shifts elicited by auditory fear conditioning. We found that cortical BF shifts were augmented, reduced, or even reversed in the shifting direction by activation of 5-HT receptors.

\section{Materials and Methods}

Experimental subject. Forty-eight adult big brown bats (Eptesicus fuscus) were used for the experiments. All experimental procedures were approved by the Institutional Animal Care and Use Committee of Washington University in St. Louis and were the same as those previously described (Gao and Suga, 2000; Ji et al., 2001).

Surgical and recording procedures. Under neuroleptanalgesia (Innovar, $4.08 \mathrm{mg} / \mathrm{kg}$ of body weight; $0.4 \mathrm{ml}$ fentanyl citrate in $20 \mathrm{mg} / \mathrm{ml}$ droperi$\mathrm{dol})$, a 1.5 -cm-long metal post was glued to the dorsal surface of the bat's skull. Experiments began 3-4 d after the surgery. An awake bat was placed in a polyethylene-foam body mold suspended at the center of a soundproof room maintained at $31^{\circ} \mathrm{C}$. The bat's head was immobilized by fixing the metal post glued on the skull onto a metal rod with set screws to ensure a uniform and stable position of the head, which directly faced a loudspeaker located $74 \mathrm{~cm}$ away. For single-unit recording, a tungsten-wire microelectrode with a tip diameter of $\sim 7 \mu \mathrm{m}$ was inserted orthogonally into the AI at a depth between 200 and $700 \mu \mathrm{m}$. Local anesthetic (5\% Lidocaine; E. Fougera, Melville, NY) and antibiotic $(0.2 \%$ Nitrofurazone; RXV Products, Westlake, TX) ointments were applied to the surgical wound. The recording session lasted 5-7 h. Water was provided with a dropper, and local anesthesia with lidocaine was refreshed every $2 \mathrm{~h}$. The bat was neither anesthetized nor tranquilized during the experiments. If the bat continued to show signs of discomfort, recordings were terminated and the bat was returned to its cage.

Acoustic stimulation. Acoustic stimuli were $20 \mathrm{~ms}$ tone bursts with a 0.5 $\mathrm{ms}$ rise-decay time delivered to the bat at a rate of four per second from a leaf tweeter with Real-Time processors version 2.1 (Tucker-Davis Technologies, Alachua, FL). Their frequencies and amplitudes were manually varied or computer controlled to measure the BF and the minimum threshold (MT) of a given neuron. The computer-controlled frequency scan consisted of $21250 \mathrm{~ms}$ time blocks. The frequency of tone bursts was randomly varied by the stimulus control and recording software (Brainware version 8.0) and was delivered every $250 \mathrm{~ms}$ in 0.5 or $1.0 \mathrm{kHz}$ steps. The amplitude of the tone bursts delivered from a leaf tweeter was calibrated with a microphone (Brüel \& Kjær Instruments, Naerum, Denmark). It was flat within $\pm 5 \mathrm{~dB}$ from 10.0 to $70.0 \mathrm{kHz}$. The amplitude of the tone burst was set at $10 \mathrm{~dB}$ above the MT of the neuron to obtain its frequency-response curve and to easily detect a BF shift. The sound pressure level was expressed in decibels sound pressure level (dB SPL) referred to $20 \mu \mathrm{Pa}$. An identical frequency scan was repeated 50 times.

Auditory fear conditioning. To evoke the BF shift of a cortical neuron, the bat was exposed to the auditory fear conditioning over 15 or $30 \mathrm{~min}$. The CS was a train of tone bursts which were $50 \mathrm{~dB}$ SPL, $10 \mathrm{~ms}$ long, 33 per second over $1.0 \mathrm{~s}$, and $5.0 \mathrm{kHz}$ lower than the $\mathrm{BF}$ of a given neuron. The US was a $50 \mathrm{~ms}$ long, $0.10-0.40 \mathrm{~mA}$ monophasic electric pulse applied to the bat's leg with a 1.0 s delay from the CS. The CS-US pair was delivered every $30 \mathrm{~s}$, so that the CS-US pair was delivered 30 or 60 times in the 15 or 30 min conditioning, respectively. The intensity of electric foot shock was just above the threshold for eliciting a just noticeable leg flexion monitored with a strain gauge. In the big brown bat, the $30 \mathrm{~min}$ conditioning elicits a large centripetal $\mathrm{BF}$ shift, but the 15 min conditioning elicits a "subthreshold" BF shift that is not large enough to be reliably detected but can be augmented to a large long-term BF shift by ACh applied to the AI (Ji et al., 2001). The CS evokes the largest centripetal BF shift when it is $\sim 5.0 \mathrm{kHz}$ lower than the $\mathrm{BF}$ of a given neuron. Therefore, the centripetal BF shift has a negative value (Gao and Suga, 2000). In each $1 \mathrm{~d}$ experiment, tone bursts alone were delivered at different frequencies and at a rate of four per second over $180 \mathrm{~min}$ to record single-unit activity. Only one neuron was studied in a $1 \mathrm{~d}$ experiment, and the same animal was used with a $3 \mathrm{~d}$ interval to minimize the cumulative effect of the conditioning. This period presumably caused the extinction of BF shifts if there were any remaining after a previous conditioning experiment.

Heart rate recording and analysis. An electrocardiogram was recorded during and after a conditioning session. Tab electrodes (Physician Sale \& Services, Jacksonville, FL) were attached to the chest and wing of a bat. Electrocardiograms were amplified by a RP2.1 enhanced real-time processor (Tucker-Davis Technologies) and stored by Brainware version 8.0 software. The heart rate change evoked by the conditioning was plotted as a function of time.

Drug applications. In the big brown bat, auditory responses can be recorded within a $2.4 \mathrm{~mm}$ diameter of the cortical area, which is mostly the AI (Dear et al., 1993). The approximate center of the AI is dorsoventrally crossed by the $30 \mathrm{kHz}$ iso- $\mathrm{BF}$ line. The approximate midpoint of this iso-BF line was first electrophysiologically located by recording auditory responses at five to six cortical loci. Then a $\sim 1.0 \mathrm{~mm}$ hole was made there for single-unit recording and drug applications. The drug applied was $0.2 \mathrm{ml}$ of $4 \mathrm{~mm} 5$-HT, $20 \mathrm{~mm} 5$-HT, $10 \mathrm{~mm} \alpha$-methyl-5-HT, or $10 \mathrm{~mm}$ ritanserin (Sigma, St. Louis, MO) dissolved in a $0.9 \%$ saline solution. Different from other drugs, ritanserin hardly dissolved in the saline solution. Therefore, the ritanserin solution was sonicated immediately before its use (Williams et al., 2002). Each of these drugs was applied to the surface of the recording site in the AI before or after the conditioning with a $1.0 \mu \mathrm{l}$ Hamilton syringe. [Williams et al. (2002) used ritanserin and MDL100,907 as the antagonists of 5-HT2A receptors and reported that ritanserin had the same effect as MDL100,907 on associate learning. Therefore, we used ritanserin.]

Data acquisition. Action potentials of a single cortical neuron tuned to a specific frequency were amplified (Medusa base station; Tucker-Davis Technologies) and selected with a time-amplitude window discriminator (Brainware version 8.0). During and after the conditioning and/or drug application, the action potentials discharged by the neuron were continuously compared with the template stored and displayed on the monitor screen at the beginning of the study of the neuron. An array of poststimulus-time histograms displays the auditory responses to the 21 tone bursts of the frequency scan repeated 50 times. It was acquired every $15 \mathrm{~min}$ up to $240 \mathrm{~min}$ after the onset of the conditioning as long as action potentials visually matched the template.

Off-line data processing. The magnitude of auditory responses of a neuron was expressed by the number of spikes per 50 identical stimuli and was plotted as a function of frequency to show the frequencyresponse curve of the neuron. The $\mathrm{BF}$ of the neuron was defined as the frequency at which the frequency-response curve peaked. To study the development of a BF shift, the BFs determined from the frequencyresponse curves obtained every $15 \mathrm{~min}$ were plotted as a function of time. The time courses of BF shifts obtained from many single neurons were averaged. Therefore, each data point in an averaged time course curve represents the mean and SE (mean $\pm \mathrm{SE}$ ) based on 50 responses multiplied by the number of single neurons used for averaging. To determine whether there were differences in response magnitude between a BF and its adjacent frequencies, or between the BFs obtained before and after the electric stimulation and/or drug application, a two-tailed unpaired $t$ test was used for a significant difference of $p<0.01$ or $p<0.05$.

According to the definition by Gao and Suga (2000), the BF shift that disappeared (i.e., recovered) within $210 \mathrm{~min}$ after the onset of a conditioning session is designated as short term, whereas the BF shift showing no sign of recovery at $210 \mathrm{~min}$ is considered long term. The conditioning usually causes an $\sim 10 \%$ decrease in overall responses right after the conditioning. The recovery of an auditory response was defined as the changed response at the $\mathrm{BF}$ recovered to that of the control response within $\pm 10 \%$.

\section{Results \\ No effect of 5-HT applied to the AI on the conditioned heart rate change}

Without a drug application, 30 min auditory fear conditioning elicited a tone-specific heart rate decrease in all four bats tested. When $30.0 \mathrm{kHz}$ tone bursts (CS) paired with electric leg stimula- 
tion (US) were delivered to the bats, their heart rate decreased $28.0 \pm 7.5 \%(n=4)$ (Fig. $1 A$, open circles). The bats showed a heart rate decrease to the $30.0 \mathrm{kHz}$ tone bursts alone $\sim 2$ min after this conditioning (Fig. $1 B$, open circles), but not to the non-CS tone bursts, such as 15.0 and 60.0 $\mathrm{kHz}$ tone bursts (Fig. 1C, open circles). Therefore, the heart rate decrease was a conditioned autonomic response specific to the CS. 5-HT ( $4 \mathrm{~mm}$ or $20 \mathrm{~mm}$ ) applied to the AI before the conditioning had no effect on this conditioned heart rate decrease $(30.0 \pm 5.8 \% ; n=4$; two-tailed $t$ test; $p>0.05)$ (Fig. 1, filled circles).

\section{Serotonergic effects on cortical auditory responses}

Without conditioning, 97 cortical neurons with BFs ranging between 19.0 and $44.0 \mathrm{kHz}($ mean $\pm \mathrm{SE}, 28.0 \pm 2.5 \mathrm{kHz})$ were examined for the effects of 5-HT (48 neurons), $\alpha$-methyl-5-HT (20 neurons), ritanserin (19 neurons), or saline (10 neurons) applied to the AI (Table 1).

Four millimolar 5-HT reduced the auditory responses at the BFs of 11 of 14 neurons studied by $29 \%$. The responses recovered to the control $\sim 45$ min after the application (Fig. 2A, open circles). Twenty millimolar 5-HT reduced the auditory responses at the BFs of 25 of 34 neurons studied by $59 \%$. The recovery time was $\sim 90 \mathrm{~min}$ (Fig. $2 \mathrm{~A}$, filled circles). Therefore, the amount and duration of the effect of 5 -HT were dose dependent. An agonist of $5-\mathrm{HT}_{2 \mathrm{~A}}$ receptors, $\alpha$-methyl-5-HT, increased the auditory responses of 15 of the 20 neurons studied by $27 \%$. These responses recovered $\sim 60 \mathrm{~min}$ later (Fig. 2A, open triangles). Conversely, an antagonist of $5-\mathrm{HT}_{2 \mathrm{~A}}$ receptors, ritanserin, decreased the auditory responses of 16 of the 19 neurons studied by $21 \%$. These responses recovered $\sim 60$ min later (Fig. $2 \mathrm{~A}$, filled triangles). All of these changes in the auditory responses were significant ( $t$ test; $p<0.05$ ). The effect of each drug on a single neuron is shown in Figure $2 B-D$.

Figure $2 B$ shows the frequency-response curves of a cortical neuron tuned to $25.0 \mathrm{kHz}$ (open circles and histogram 1). The auditory responses of all frequencies were reduced by $20 \mathrm{~mm}$ 5-HT (filled circles and histogram 2) and then recovered $\sim 90$ min after the 5-HT application (dashed curve and histogram 3 ). The responses at the BF were decreased by $\sim 46 \%$. Figure $2 C$ shows that $\alpha$-methyl-5-HT increased the response at the $\mathrm{BF}$ of a neuron tuned to $29.0 \mathrm{kHz}$ (open and filled circles; histograms 1 and 2). The response recovered $\sim 60$ min after the application (dashed curve and histogram 3). In Figure $2 D$, ritanserin reduced the response at the $\mathrm{BF}$ of a neuron tuned to $23.0 \mathrm{kHz}$ by $24 \%$ (open vs filled circles; histogram 1 vs 2 ). The response recovered $\sim 60$ min after the drug application (dashed curve and histogram 3 ).

Without acoustic stimulation, none of the drugs applied to the AI evoked a BF shift as did ACh applied to the AI (Ji et al., 2001). To evoke the BF shift (Zhang and Suga, 1997) and the shift of delay-tuning curves (Yan and Suga, 1999), the selective activation of a small group of cortical neurons by a tonal stimulus was necessary.
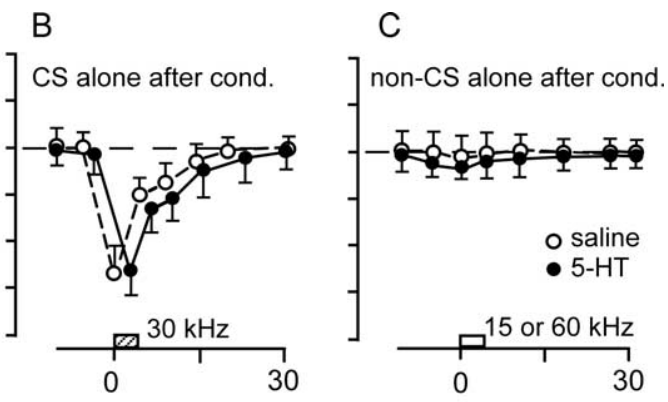

onset of conditioning $(A)$ or a train of tone bursts ( $B$ and $C$ )

Figure 1. A conditioned heart rate change was not affected by 5 -HT applied to the Al. $A, A$ heart rate decrease elicited by the 30 min conditioning (cond.): a CS ( $30 \mathrm{kHz}$; hatched rectangle) paired with a US (filled rectangle). $\boldsymbol{B}, \mathrm{A}$ heart rate decrease for the $\mathrm{CS}$ 作

Table 1. Effects of 5-HT, $\alpha$-methyl-5-HT, and ritanserin on cortical neurons

$\mathrm{BF}$ shift (kHz) elicited by:

\begin{tabular}{ccl} 
& BF shift (kHz) elicited by: & \\
\cline { 2 - 3 } \% Change in resp. at BF & 15 min conditioning & 30 min conditioning \\
\hline$-2.0 \pm 1.0(10 / 10)$ & $0.0 \pm 0.1(12 / 12)$ & $-1.8 \pm 0.1(10 / 10)$ \\
$-28.6 \pm 4.8(11 / 14)^{* *}$ & $-1.5 \pm 0.2(16 / 20)^{* *}$ & Not studied \\
$-58.8 \pm 4.3(25 / 34)^{* *}$ & $0.0 \pm 0.1(12 / 12)$ & $-0.7 \pm 0.1(17 / 22)^{*}$ \\
$26.9 \pm 5.6(15 / 20)^{* *}$ & $-1.8 \pm 0.2(18 / 27)^{* *}$ & $-1.8 \pm 0.2(14 / 18)$ \\
$-20.5 \pm 4.3(16 / 19)^{*}$ & $+1.0 \pm 0.2(10 / 12)^{*}$ & $+1.0 \pm 0.1(18 / 23)^{* *}$ \\
\hline
\end{tabular}

hanges in response magnitude and conditioning-elicited cortical BF shift evoked by 5-HT, $\alpha$-methyl-5-HT, and ritanserin. Response (resp.) magnitude (number of spikes per 50 tone bursts) is expressed in percentage of change compared with the response in the control condition. A BF shift (mean $\pm \mathrm{SE}$ ) was either centripetal (negative) or centrifugal (positive). The numbers in parentheses are the number of neurons affected by a drug out of the total number of ared with the effect of saline (i.e., the control) for ${ }^{*} p<0.05$ or ${ }^{* *} p<0.01$.

\section{Effects of different doses of 5-HT on BF shifts}

As described in the Materials and Methods, 15 min conditioning elicited subthreshold cortical BF shifts. A saline solution applied to the AI had no effect on these subthreshold BF shifts $(n=12$; $p>0.05$ ) (Table 1). To examine the effect of a low dose of 5-HT on the subthreshold BF shift, $4 \mathrm{~mm} 5$-HT was applied to the AI before the $15 \mathrm{~min}$ conditioning. It was found that subthreshold BF shifts were augmented in 16 of the 20 neurons studied, and the remaining four neurons showed no changes in the BF and response magnitude. Eight of the 16 neurons showed long-term BF shifts (Fig. 3A, open triangles). Their response at the control BF $\left(\mathrm{BF}_{\mathrm{c}}\right)$ decreased by 22 to $40 \%$ after the conditioning (Fig. $3 A$, open circles), whereas that at the shifted $\mathrm{BF}\left(\mathrm{BF}_{\mathrm{s}}\right)$ initially decreased by $\sim 18 \%$ and then increased up to $38 \%$ (Fig. $3 A$, filled circles). Another eight neurons showed short-term BF shifts (Fig. $3 B$, open triangles). The changes in the responses at the $\mathrm{BF}_{\mathrm{c}}$ and $\mathrm{BF}_{\mathrm{s}}$ were small and short (Fig. $3 B$, open and filled circles).

Figure 3, $C$ and $D$, respectively, show the two types of changes in the frequency-response curves of single neurons evoked by 4 $\mathrm{mm}$ 5-HT applied to the AI before the $15 \mathrm{~min}$ conditioning. In Figure $3 C$, the auditory response of the neuron tuned to $34.0 \mathrm{kHz}$ (open circles) was initially reduced between 30.0 and $36.0 \mathrm{kHz}$ (filled circles). This reduction was caused by the applied drug. However, $\sim 60 \mathrm{~min}$ after the onset of the conditioning, the response at $32.0 \mathrm{kHz}$ increased by $48 \%$. Thus, the BF of the neuron shifted from 34.0 to $32.0 \mathrm{kHz}$ (dashed curve) (i.e., toward the 29.0 $\mathrm{kHz}$ CS). This BF shift was long term and caused by the conditioning. Of the 16 neurons studied in the same way, eight showed identical changes as those shown in Figure $3 C$. In Figure 3D, the neuron was tuned to $26.0 \mathrm{kHz}$ (open circles). Its BF first shifted to $24.0 \mathrm{kHz}$ (filled circles) (i.e., toward the $21.0 \mathrm{kHz} \mathrm{CS}$ ) and then 

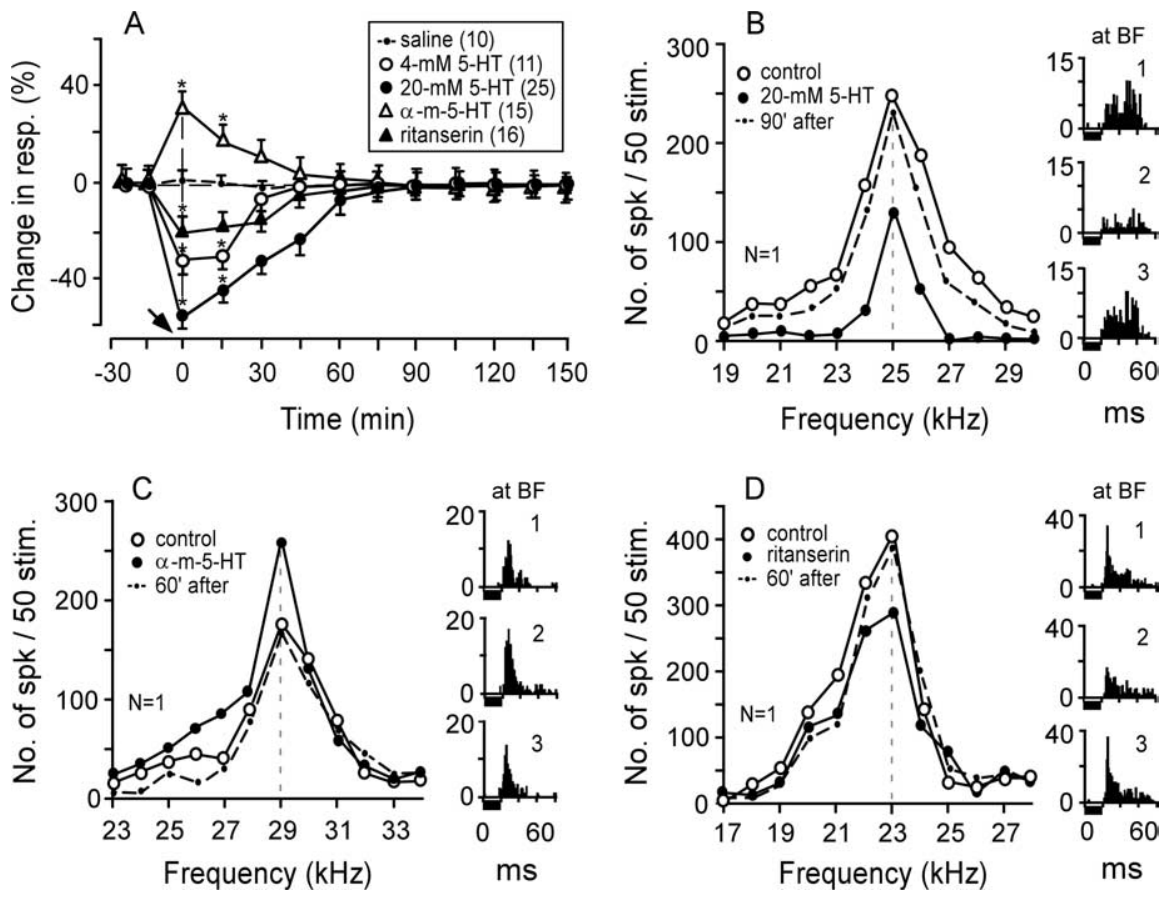

Figure 2. Changes in response magnitude evoked by 5-HT, $\alpha$-methyl-5-HT, or ritanserin. $\boldsymbol{A}$, The change (mean $\pm \mathrm{SE}$ ) in response (number of spikes per 50 tone bursts) is expressed in percentage of spikes per 50 tone bursts compared with the response in the control condition ( ${ }^{*} p<0.01$ ). The arrow along the time axis indicates when a drug was applied to the Al. The inset shows the symbols indicating the drugs applied to the Al and the number of single neurons affected by a drug. $\alpha-\mathrm{m}-5-\mathrm{HT}, \alpha-$ Methyl-5HT. $\boldsymbol{B}-\boldsymbol{D}$, The frequency-response curves and poststimulus-time histograms (1-3) displaying the responses at the BFs of three single neurons were recorded before (control), $5 \mathrm{~min}$ after, and 60 or 90 min after a drug application. Each horizontal bar under the histogram represents a 20 ms tone burst fixed at $10 \mathrm{~dB}$ above the MT of a given neuron. N, Number of neurons studied; resp., response; stim., stimulation; No., number; spk, spike.
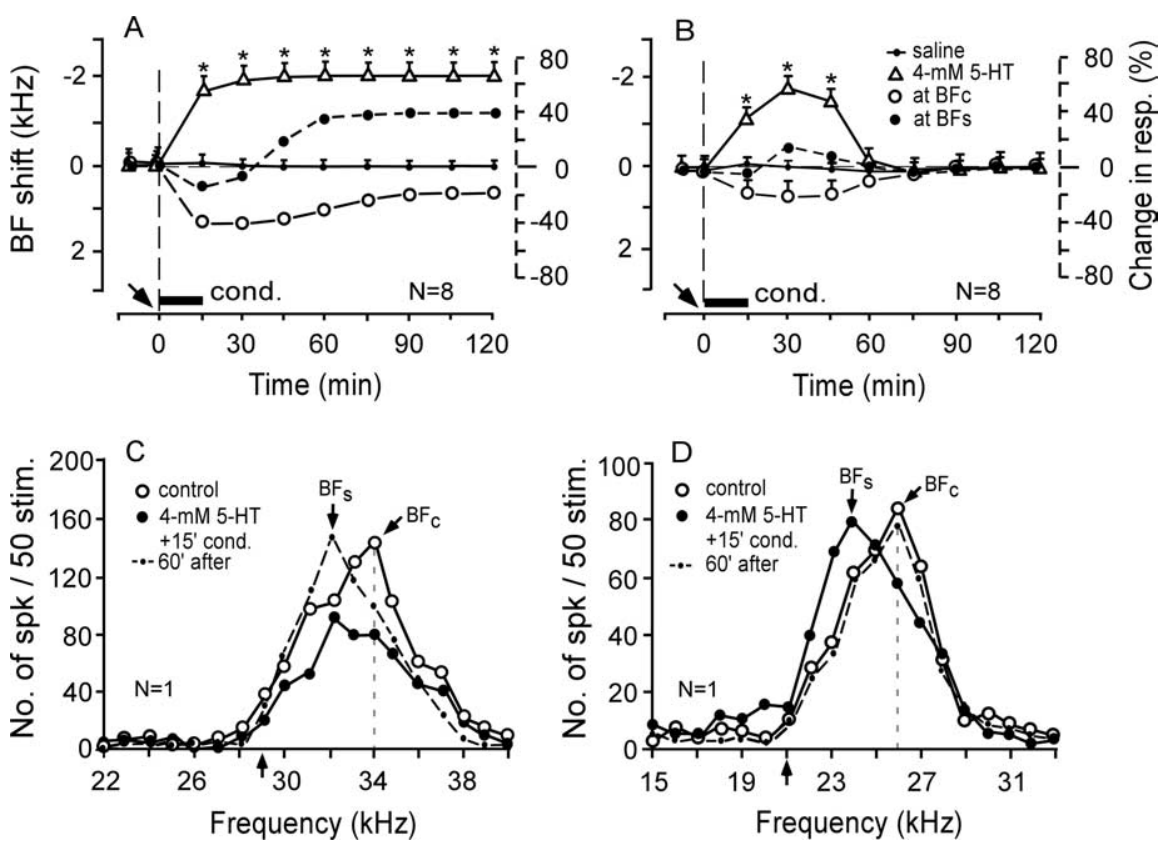

Figure 3. Effects of $4 \mathrm{~mm} 5-\mathrm{HT}$ on the frequency-response curves and subthreshold BF shifts elicited by the 15 min conditioning $\boldsymbol{A}-\boldsymbol{D}$, Four millimolar 5 -HT evoked either a long-term centripetal BF shift $(\boldsymbol{A}, \boldsymbol{C})$ or short-term centripetal BF shift $(\boldsymbol{B}, \boldsymbol{D}) . \boldsymbol{A}, \boldsymbol{B}, \mathrm{BF}$ shifts refer to the left vertical axes, percentage of changes in response at the $B F_{c}$ (open circles) and $B_{s}$ (filled circles) refer to the right vertical axes. N, Number of neurons studied. The arrow and horizontal bar along the time axis indicates the time of a drug application to the Al and the conditioning (cond.), respectively. $\boldsymbol{C}, \boldsymbol{D}$, Changes in the frequency-response curves of two single neurons tuned to 34.0 or $26.0 \mathrm{kHz}$, respectively. The upward arrows along the frequency axis indicate the frequencies of CS tone bursts. See Figure 2 legend for the symbols and abbreviations. recovered $\sim 60$ min after the onset of the conditioning (dashed curve). The remaining eight of the 16 neurons showed the same changes as those shown in Figure 3D.

With the expectation that a high dose of 5-HT might augment the subthreshold BF shift more than the $4 \mathrm{~mm}$ 5-HT did, 20 mM 5-HT was applied to the AI before the 15 min conditioning. It was then found that the subthreshold BF shifts of all 12 cortical neurons studied were not augmented. That is, no BF shifts were elicited (Table 1; Fig. $4 A$, open triangles). In Figure $4 C, 20 \mathrm{~mm}$ 5-HT applied to the AI before the 15 min conditioning significantly reduced the overall response of a single neuron tuned to $24.0 \mathrm{kHz}$, but it did not evoke any BF shift (open vs filled circles).

For the $30 \mathrm{~min}$ conditioning, the $\mathrm{BF}$ shift slowly developed to a plateau of $1.8 \pm$ $0.1 \mathrm{kHz} \sim 75$ min after the onset of the conditioning and was sustained for $>3 \mathrm{~h}$ (Ji et al., 2001). Such a BF shift was not affected by a saline solution applied to the AI $(n=10)$ (Table 1$)$. Because $20 \mathrm{~mm}$ 5-HT did not augment the subthreshold BF shift elicited by the 15 min conditioning, it was applied to the AI before the 30 min conditioning. Twenty millimolar 5-HT completely blocked the development of long-term BF shifts in five of the 22 cortical neurons studied (data not shown in Fig. 4) and reduced and shortened the BF shifts in the remaining 17 neurons (Table 1; Fig. $4 B$, open triangles). For these 17 cortical neurons, the BF shifts peaked at $-0.7 \pm 0.1 \mathrm{kHz}$ and lasted $90 \pm$ 5.0 min. In Figure 4D, $20 \mathrm{~mm}$ 5-HT applied to the AI before the $30 \mathrm{~min}$ conditioning significantly reduced the auditory response of a neuron tuned to $23.0 \mathrm{kHz}$ (open circles) and temporarily shifted its BF toward the $18.0 \mathrm{kHz}$ CS (filled circles and dashed curve).

\section{Effect of $20 \mathrm{~mm} 5$-HT applied after the $30 \mathrm{~min}$ conditioning on long-term BF shifts}

Because $20 \mathrm{~mm}$ 5-HT drastically reduced the development of the long-term BF shift as described above, its effect was further studied on the BF shift that had developed to the midpoint of the plateau or to the plateau after the $30 \mathrm{~min}$ conditioning. Without a drug application, the BF shift elicited by the 30 min conditioning develops up to $\sim 50 \%$ of the plateau value $\sim 35$ min after the onset of the conditioning and reaches the plateau at $\sim 75$ min after the onset of the conditioning (Fig. 5A, dashed curve with dots) (Ji and Suga, 2003).

Twenty millimolar 5-HT applied to the AI at $35 \mathrm{~min}$ after the onset of the 
conditioning evoked a $1.0 \pm 0.2 \mathrm{kHz} \mathrm{BF}$ shift instead of a $1.8 \pm 0.1 \mathrm{kHz}$ BF shift in 15 of the 19 cortical neurons studied ( $p<$ $0.05)$. Seven of these 15 neurons maintained this $1.0 \mathrm{kHz}$ BF shift for $45 \mathrm{~min}$ at the plateau. Then, their BFs fully recovered $\sim 165$ min after the onset of the conditioning (Fig. $5 \mathrm{~A}$, filled squares). However, the remaining eight neurons maintained the $1.0 \mathrm{kHz}$ BF shift for $\geq 135$ min (Fig. 5A, open squares). In Figure $5 B$, a cortical neuron tuned to $26.0 \mathrm{kHz}$ showed a BF shift from 26.0 to $25.0 \mathrm{kHz}$ [i.e., toward the $21.0 \mathrm{kHz} \mathrm{CS}$, at the end of the 30 min conditioning (open vs filled circles)]. When $20 \mathrm{~mm}$ 5-HT was applied to the AI at this time, the auditory response of the neuron drastically decreased at the frequencies between 19.0 and 34.0 $\mathrm{kHz}$, but the $\mathrm{BF}_{\mathrm{s}}$ stayed at $25.0 \mathrm{kHz}$ (small dots). The response recovered $\sim 90 \mathrm{~min}$ after the onset of the conditioning (dashed curve). However, $20 \mathrm{~mm}$ 5-HT applied at $\sim 75$ min after the onset of the 30 min conditioning had no effect on the long-term BF shifts of all 10 neurons studied ( $p>$ 0.01 ) (Fig. $5 A$, open diamonds), although it drastically reduced their auditory responses.

Effect of $10 \mathrm{~mm} \alpha$-methyl-5-HT applied before the 15 or $30 \mathrm{~min}$ conditioning on BF shifts

An agonist of $5-\mathrm{HT}_{2 \mathrm{~A}}$ receptors, $\alpha$-methyl-5-HT, applied to the AI before the 15 min conditioning augmented the subthreshold BF shift and evoked a shortterm centripetal BF shift in 18 of the 27 cortical neurons studied (Table 1). The BF shift was $1.8 \pm 0.2 \mathrm{kHz}$ at the peak and lasted $105 \pm 3.5 \min (n=18 ; p<0.01)$ (Fig. 6A, open triangles). There was no effect on the auditory responses and BFs of the remaining nine neurons (data not shown in Fig. 6). In Figure 6C, $\alpha$-methyl5 - $\mathrm{HT}$ reduced the response at the $\mathrm{BF}_{c}$ $(23.0 \mathrm{kHz})$ of a cortical neuron and augmented the response at $22.0 \mathrm{kHz}$ (filled circles). These frequency-dependent changes in the responses caused the BF to shift from 23.0 to $22.0 \mathrm{kHz}$ (i.e., toward the 18.0 $\mathrm{kHz}$ CS). They disappeared (i.e., the responses recovered) $\sim 90$ min after the onset of the conditioning (dashed curve).

$\alpha$-methyl-5-HT applied to the AI before the 30 min conditioning augmented the centripetal BF shift in 14 of the 18 cortical neurons studied (Table 1). The augmented BF shift developed faster than the $\mathrm{BF}_{\mathrm{c}}$ shift (Fig. $6 \mathrm{~B}$, open triangles vs small dots) $(p<0.05)$, but the amount of the augmented BF shift at the plateau was the same as that of the $\mathrm{BF}_{\mathrm{c}}$ shift $(p>0.05)$. In Figure $6 \mathrm{D}$, a cortical neuron tuned to $33.0 \mathrm{kHz}$ (open circles) increased its response at $31.0 \mathrm{kHz}$ by $\sim 68 \%$, which led to a $2.0 \mathrm{kHz}$ longterm centripetal BF shift (filled circles). The overall response was reduced slightly $\sim 210 \mathrm{~min}$ after the onset of the conditioning (dashed curve).
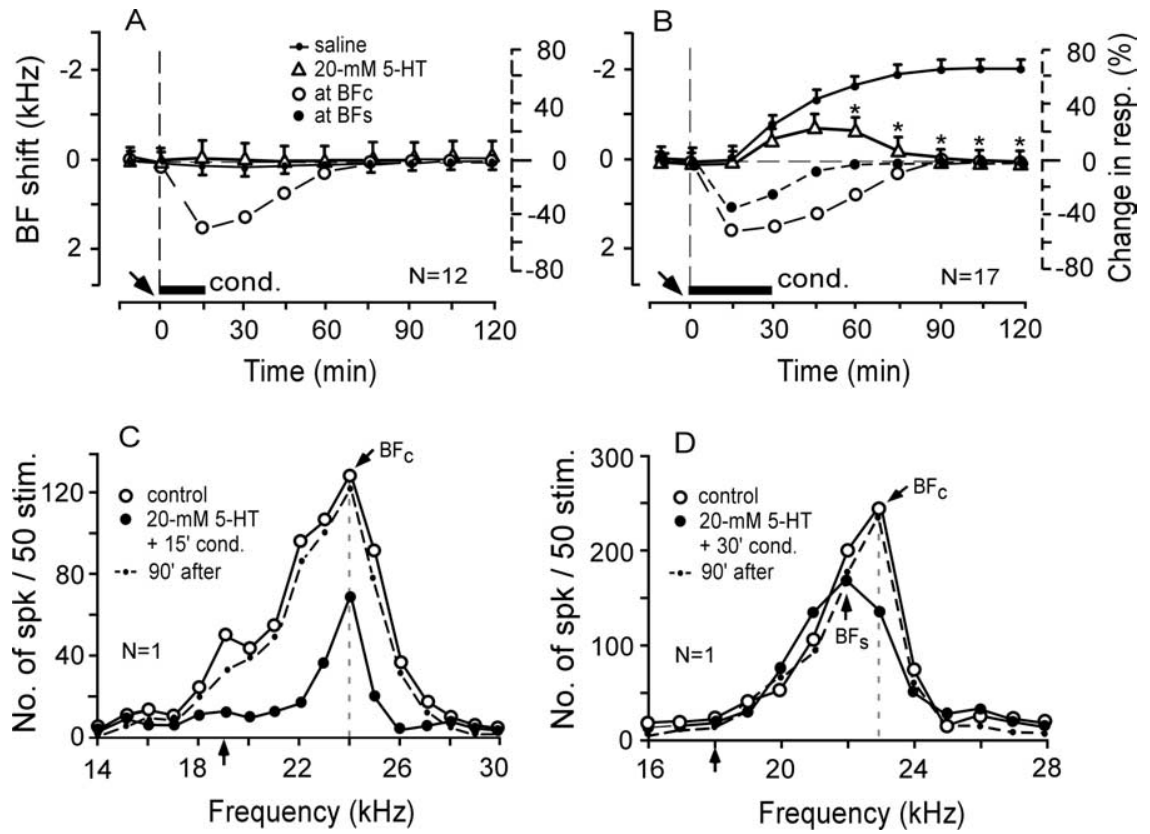

Figure 4. Effects of $20 \mathrm{~mm} 5$-HT on the subthreshold BF shifts elicited by the 15 min conditioning and the large long-term BF frequency-response curves of two single neurons tuned to 24.0 or $23.0 \mathrm{kHz}$, respectively. See Figures 2 and 3 legends for
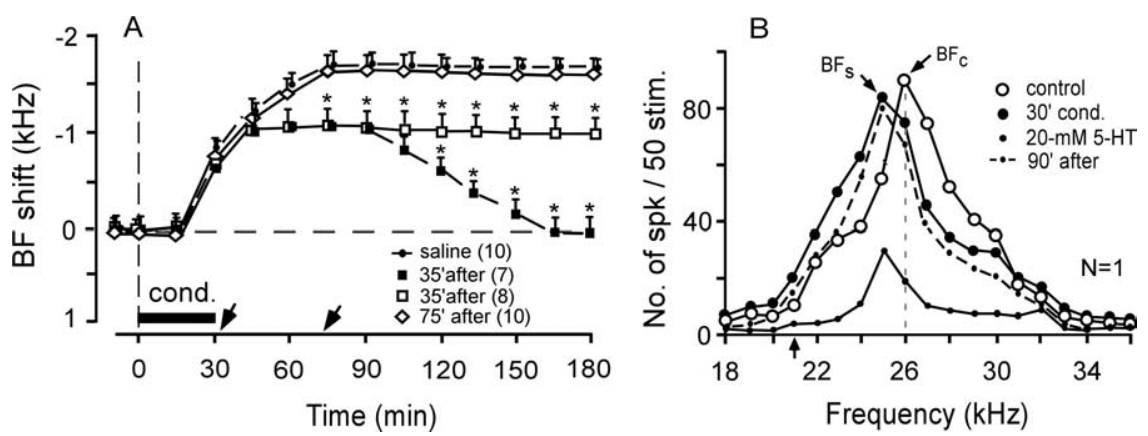

Figure 5. Effects on the BF shifts elicited by the 30 min conditioning of $20 \mathrm{~mm} 5-\mathrm{HT}$ applied to the Al after the $30 \mathrm{~min}$ conditioning. A, 5-HT applied to the $\mathrm{Al} 35 \mathrm{~min}$ after the onset of the conditioning decreased the magnitude of the long-term $\mathrm{BF}$ shift in eight neurons (open squares) and changed the long-term BF shift into a short-term BF shift in seven neurons (filled cortical neuron tuned to $26.0 \mathrm{kHz}$ (open circles) shifted its BF to $25.0 \mathrm{kHz}$ (filled circles) at the end of the conditioning. $5-\mathrm{HT}$ applied to the $\mathrm{Al} 35 \mathrm{~min}$ after the onset of the conditioning transiently reduced its auditory responses, but its BF stayed at $25.0 \mathrm{kHz}$ (small dots). See Figures 2 and 3 legends for the symbols and abbreviations.

\section{Effect of $10 \mathrm{~mm}$ ritanserin applied before the conditioning on} BF shifts

An antagonist of 5- $\mathrm{HT}_{2 \mathrm{~A}}$ receptors, ritanserin, applied to the $\mathrm{AI}$ before the 15 min conditioning evoked a small short-term "centrifugal" BF shift in 10 of the 12 neurons studied. The BF shift was $1.0 \pm 0.2 \mathrm{kHz}$ and the recovery time was $45 \pm 8.5 \mathrm{~min}$ (Fig. $7 \mathrm{~A}$, filled triangles). Ritanserin did not change the responses and $\mathrm{BFs}$ of the remaining two neurons. Figure $7 C$ shows the centrifugal $B F$ shift of a single neuron tuned to $29.0 \mathrm{kHz}$. The $\mathrm{BF}$ at $29.0 \mathrm{kHz}$ (open circles) shifted to $30.0 \mathrm{kHz}$ [i.e., away from the $24.0 \mathrm{kHz} \mathrm{CS}$ (filled circles)].

Ritanserin applied to the AI before the 30 min conditioning also evoked the centrifugal BF shift in 18 of the 23 neurons studied. This centrifugal BF shift was $1.0 \pm 0.1 \mathrm{kHz}$ and disappeared (i.e., recovered) in $\sim 75 \mathrm{~min}$ after the onset of the conditioning 

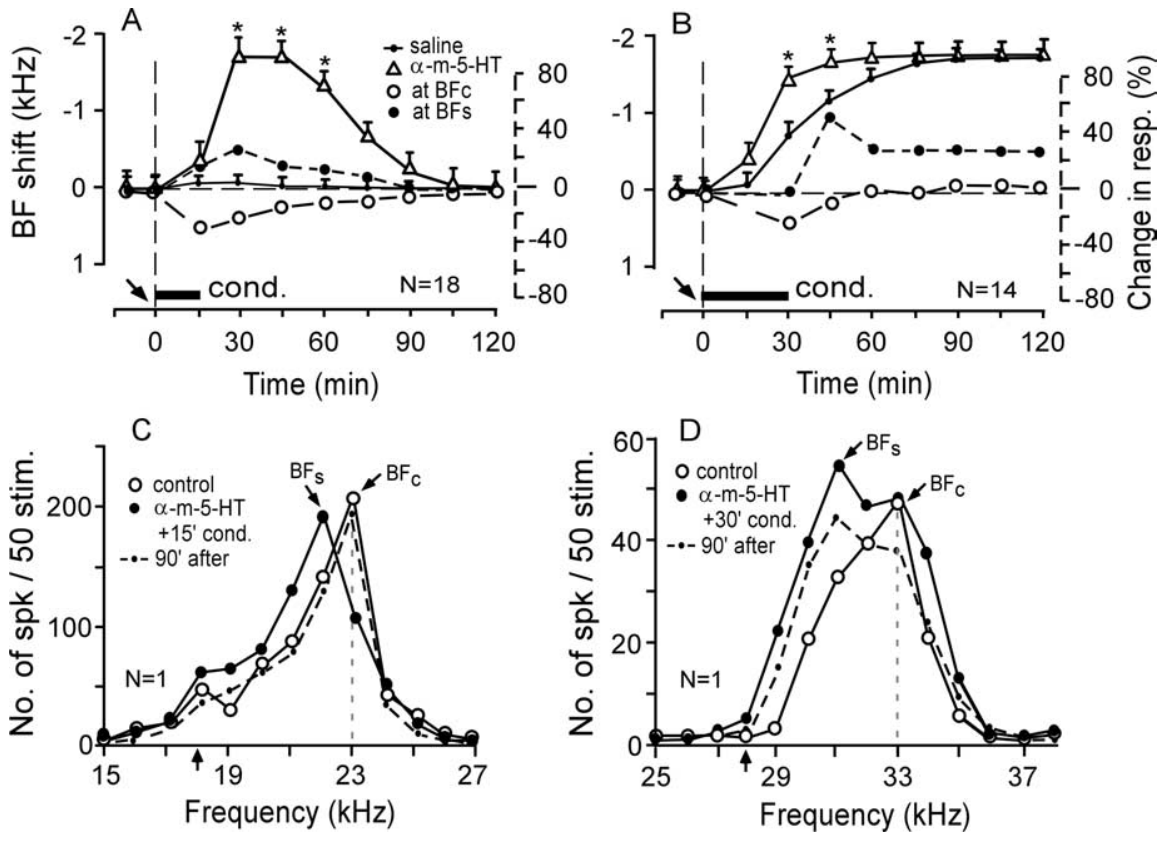

Figure 6. Effects of $\alpha$-methyl-5-HT (an agonist of $5-\mathrm{HT}_{2 \mathrm{~A}}$ receptors) on the subthreshold $\mathrm{BF}$ shifts elicited by the $15 \mathrm{~min}$ conditioning $(\boldsymbol{A}, \boldsymbol{C})$ or the long-term BF shifts elicited by the 30 min conditioning $(\boldsymbol{B}, \boldsymbol{D})$. $\alpha$-Methyl-5-HT augmented the subthreshold-BF shifts elicited by the 15 min conditioning ( $A$, open triangles) and the BF shift elicited by the 30 min conditioning ( $\boldsymbol{B}$, open triangles). $\boldsymbol{C}, \boldsymbol{D}$, The effect of $10 \mathrm{~mm} \alpha$-methyl-5-HT applied before 15 or 30 min conditioning on the frequency-response curves of two single neurons tuned to 23.0 or $33.0 \mathrm{kHz}$. See Figures 2 and 3 legends for the symbols and abbreviations.
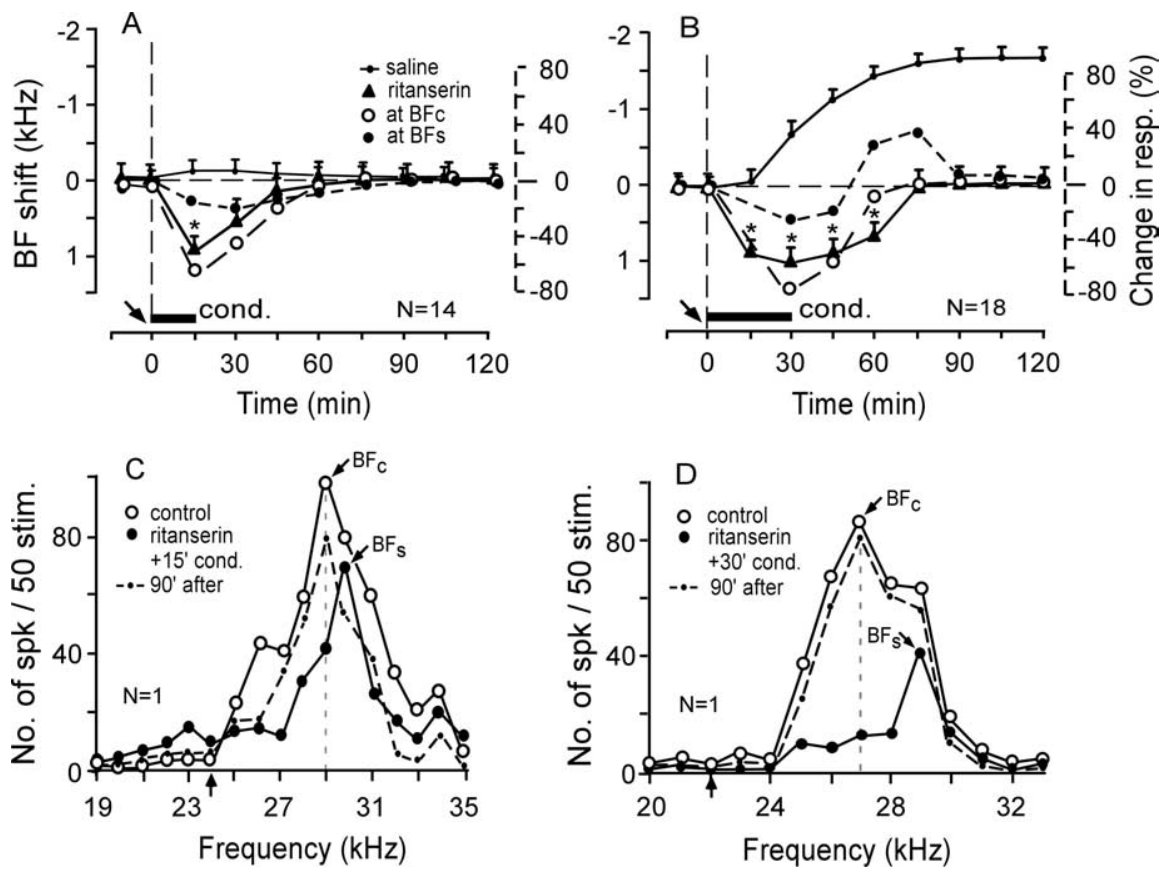

Figure 7. Effects of ritanserin (an antagonist of $5-\mathrm{HT}_{2 \mathrm{~A}}$ receptors) on the subthreshold $\mathrm{BF}$ shifts elicited by the 15 min conditioning $(\boldsymbol{A}, \boldsymbol{C})$ or the long-term BF shifts elicited by the 30 min conditioning $(\boldsymbol{B}, \boldsymbol{D}) . \boldsymbol{A}, \boldsymbol{B}$, The time courses of the BF shifts (solid lines) and changes in response magnitude (dashed lines). Ritanserin changed the subthreshold BF shift to the small centrifugal $B F$ shift ( $\boldsymbol{A}$, filled triangles) and reversed the direction of the BF shift evoked by the 30 min conditioning ( $\boldsymbol{B}$, filled triangles). $\boldsymbol{C}, \boldsymbol{D}$, The effect of $10 \mathrm{~mm}$ ritanserin applied before the 15 or 30 min conditioning on the frequency-response curves of two single neurons tuned to 29.0 or $27.0 \mathrm{kHz}$. See Figures 2 and 3 legends for the symbols and abbreviations.

(Table 1; Fig. $7 B$, filled triangles). The centrifugal BF shift at the peak was the same as that evoked by ritanserin paired with the 15 min conditioning but lasted $\sim 30$ min longer than the latter. In Figure $7 D$, a cortical neuron tuned to $27.0 \mathrm{kHz}$ (open circles) decreased its responses to tone bursts between 25.0 and $29.0 \mathrm{kHz}$ after a ritanserin application to the AI before the $30 \mathrm{~min}$ conditioning. The decrease in response was largest at $27.0 \mathrm{kHz}$ and smallest at 29.0 $\mathrm{kHz}$ (filled circles). Accordingly, the $\mathrm{BF}$ of the neuron shifted from 27.0 to $29.0 \mathrm{kHz}$ (i.e., away from the $22.0 \mathrm{kHz}$ CS). The recovery time of the BF shift was $\sim 75 \mathrm{~min}$.

\section{Discussion}

Effect of 5-HT applied to the AI on the conditioned heart rate change

Both the AI and auditory thalamus project to the amygdala, which in turn projects to many places in the brain to evoke conditioned autonomic and behavioral responses (LeDoux et al., 1984; Inoue et al., 1993; Stutzmann et al., 1999). The thalamo-amygdala projection plays an essential role in a conditioned heart rate change, but the cortico-amygdala projection does not, because a lesion of the neocortex does not interfere with the acquisition and maintenance of conditioned autonomic responses (DiCara et al., 1970; Berntson et al., 1983). Therefore, our data, which showed no effect of 5-HT applied to the $\mathrm{AI}$ on the conditioned heart rate change, is compatible with the above finding. Although auditory fear conditioning elicits an increase in the 5-HT level of the AI (Stark and Scheich, 1997), this increase is apparently not directly related to the conditioned heart rate change, but to the modulation of cortical plasticity as described below.

\section{Neural mechanism of serotonergic} modulation of the BF shift elicited by auditory fear conditioning

To evoke the cortical BF shift, the selective activation of a small group of cortical neurons by a tonal or electrical stimulation is necessary. The amount and duration of the BF shift are modulated by the serotonergic and cholinergic systems. Without the tonal or cortical electric stimulation, neither ACh nor 5-HT applied to the AI evokes the BF shift.

The effect of any of the drugs used on the responses to tone bursts was largest immediately after their application to the AI and disappeared within 60 min thereafter. It was frequency-independent. However, the cortical BF shift elicited by the $30 \mathrm{~min}$ conditioning gradually increased over $60 \mathrm{~min}$ after the onset of conditioning and reached a plateau which lasted more than several hours. It was frequency-dependent because it depended on the decrease in the response at the $\mathrm{BF}_{\mathrm{c}}$ and the increase in the response at the $\mathrm{BF}_{\mathrm{s} .}$ Therefore, the $\mathrm{BF}$ shift occurred regardless of a frequency-independent decrease or increase in the response 
evoked by 4 mм 5-HT or $\alpha$-methyl-5-HT. Because the development of the cortical BF shift greatly depends on the increase in cortical ACh that occurs within $60 \mathrm{~min}$ after the onset of the conditioning (Ji et al., 2001; Ji and Suga, 2004), the drugs used in our current research affected the development of the BF shift in the initial $40 \mathrm{~min}$ or so and had a long-lasting effect on the BF shift. Therefore, the time course of the drug effect on the response magnitude was quite different from that on the BF shift.

Our current data are not sufficient enough to propose a model for serotonergic modulation of the cortical BF shift. However, we may speculate the mechanism for the serotonergic modulation. The direction of the BF shift depends on the balance between excitation and inhibition occurring in the AI, because muscimol (an agonist of $\mathrm{GABA}_{\mathrm{A}}$ receptors) changes the centripetal BF shift into a centrifugal BF shift (Ma and Suga, 2004), and bicucullin (an antagonist of $\mathrm{GABA}_{\mathrm{A}}$ receptors) changes the centrifugal $\mathrm{BF}$ shift into a centripetal BF shift (Xiao and Suga, 2002; Ma and Suga, 2004). Ritanserin (a $5-\mathrm{HT}_{2 \mathrm{~A}}$ receptor antagonist) suppressed the cortical auditory response and changed the centripetal BF shift into a centrifugal BF shift. It presumably reduced the activity of $5-\mathrm{HT}_{2 \mathrm{~A}}$ receptors and led to a relative increase in the cortical inhibition by the GABAergic neurons. $\alpha$-methyl-5-HT (a $5-\mathrm{HT}_{2 \mathrm{~A}}$ receptor agonist), which augmented the cortical auditory response and centripetal BF shift, presumably increased the excitation of the cortical pyramidal neurons through $5-\mathrm{HT}_{2 \mathrm{~A}}$ receptors. $\alpha$-methyl-5-HT has a moderate affinity for $5-\mathrm{HT}_{2 \mathrm{C}}$ receptors but a high affinity for $5-\mathrm{HT}_{2 \mathrm{~A}}$ receptors (Garnovskaya et al., 1995). Therefore, we simply interpreted that the effect of $\alpha$-methyl-5-HT was because of the activation of $5-\mathrm{HT}_{2 \mathrm{~A}}$ receptors.

There are at least three types of cortical GABAergic neurons: those with $5-\mathrm{HT}_{3}$ or $5-\mathrm{HT}_{2 \mathrm{~A}}$ receptors and those without $5-\mathrm{HT}_{3} /$ $5-\mathrm{HT}_{2 \mathrm{~A}}$ receptors (Jakab and Goldman-Rakic, 2000). 5-HT applied to the AI decreased the auditory response. This decrease in the response may be because of $5-\mathrm{HT}_{2 \mathrm{~A}}$ and/or $5-\mathrm{HT}_{3}$ receptors located on GABAergic neurons. Layer $\mathrm{V}$ pyramidal neurons have abundant $5-\mathrm{HT}_{2 \mathrm{~A}}$ receptors and may be excited by 5-HT (Aghajanian and Marek, 1997, 2000). Four millimolar 5-HT augmented the BF shift, but $20 \mathrm{~mm}$ 5-HT reduced the BF shift. To explain these observations, we have to assume that the affinity of 5- $\mathrm{HT}_{3}$ receptors on the GABAergic neurons for 5-HT was lower than that of $5-\mathrm{HT}_{2 \mathrm{~A}}$ receptors (Glennon et al., 2000) and that only higher levels of 5-HT activated GABAergic neurons through $5-\mathrm{HT}_{3}$ receptors. Four millimolar 5-HT weakly excited the GABAergic neurons and excited the pyramidal neurons via $5-\mathrm{HT}_{2 \mathrm{~A}}$ receptors, which in turn activated cortical cholinergic endings so that the subthreshold BF shift changed into a suprathreshold BF shift. However, $20 \mathrm{~mm}$ 5-HT strongly excited the GABAergic neurons via $5-\mathrm{HT}_{3}$ receptors so that the $\mathrm{BF}$ shift was reduced. The serotonergic modulation of the cortical $\mathrm{BF}$ shift presumably depends on the balance between the excitation evoked by the pyramidal neurons through the activation of $5-\mathrm{HT}_{2 \mathrm{~A}}$ receptors and the inhibition evoked by the GABAergic neurons through the activation of $5-\mathrm{HT}_{3}$ receptors.

\section{The effects of 5-HT and stress on cortical plasticity}

It has been shown that (1) a 30 min electric footshock induces 5-HT release in the brain, but a 15 min electric footshock does not (Dunn, 1988; Inoue et al., 1993, 1994); (2) a 60 min electric foot-shock induces severe stress (Malyszko et al., 1994) and; (3) the 30 min auditory fear conditioning with tone bursts and an electric footshock evokes a large, long-lasting cortical BF shift (Gao and Suga, 2000). These findings indicate that the cortical
5-HT level is influenced by the level of stress and suggest that the large, long-lasting BF shift occurs in a mildly stressful situation caused by the 30 min conditioning. Our current studies show that $20 \mathrm{~mm}$ 5-HT blocked the long-term BF shift, whereas 4 mM 5-HT changed the subthreshold BF shift into a suprathreshold BF shift. These findings may be interpreted as follows: the 30 min conditioning mildly stressed the animal and evoked a small increase in the cortical 5-HT levels, which increased the development of the long-term BF shift augmented by ACh. However, 20 mm 5-HT applied to the AI before the $30 \mathrm{~min}$ conditioning caused a large increase in the 5-HT level, as did strong stressors, and suppressed the development of the BF shift. However, the 15 min conditioning weakly stressed the animal and evoked the subthreshold BF shift. Four millimolar 5-HT applied to the AI before the conditioning caused a small increase in the cortical 5-HT level and changed the subthreshold BF shift into the suprathreshold BF shift. We hypothesize that a functional role of cortical 5-HT is to suppress the plasticity of the AI (i.e., auditory learning) in strongly stressful situations but to facilitate it in weakly stressful situations. It has been reported that cortical plasticity is influenced by not only stress but also attention, arousal, and motivation (Polley et al., 2006).

\section{Interaction between $\mathrm{ACh}$ and 5-HT for modulation of cortical BF shifts}

Each cortical neuron has several thousand synapses on the dendrites for information processing (Kandel, 2000). The BF of a neuron is probably determined by the most dominant excitatory input (synapse) in an array of frequency-labeled inputs. The BF shift occurs presumably because of a shift of the dominant input along the array of the inputs according to a change in synaptic connectivity and/or the formation of new synapses (Engert and Bonhoeffer, 1999; Maletic-Savatic et al., 1999). Serotonergic and cholinergic synapses are mostly located on the spines and dendritic shafts of pyramidal neurons and modulate activitydependent synaptic changes (Rasmusson, 2000; Gu, 2002). Thus, these two neuromodulators presumably interact with each other during the development of the BF shift.

The CS (tone bursts) excites a specific cortical input. Then, the cortical neural net and corticofugal feedback produce the cortical $\mathrm{BF}$ shift, which is, in turn, augmented by ACh released from the neurons in the nucleus basalis (Gao and Suga, 2000; Suga and Ma, 2003). Muscarinic ACh receptors play an important role in this augmentation because atropine applied to the AI immediately before the 30 min conditioning abolishes the development of the long-term cortical BF shift (Ji et al., 2001). Atropine applied to the AI $\sim 35 \mathrm{~min}$ after the onset of the conditioning reduces the long-term cortical BF shift and changes it to short term; atropine applied to the $\mathrm{AI} \sim 55 \mathrm{~min}$ after the onset of the conditioning reduces the amount of the cortical $\mathrm{BF}$ shift without changing it into short term; and atropine applied to the AI $\sim 70$ min after the onset of the conditioning transiently reduces the cortical BF shift elicited by the conditioning (Ji and Suga, 2003). In comparison, $20 \mathrm{~mm} 5$-HT applied to the AI $\sim 35 \mathrm{~min}$ after the 30 min conditioning reduced the long-term $\mathrm{BF}$ shift and, in addition, made it short term in 33\% of the neurons studied; and 5-HT applied to the AI $\sim 75$ min after the conditioning had no effect on it at all. These findings indicate that the cholinergic and serotonergic neuromodulator systems can alter the cortical BF shift, interacting with each other only during the development of the BF shift.

Serotonergic neurons in the raphe nuclei project both to the cortical sensory neurons (Barnes and Sharp, 1999) and the cholinergic neurons in the nucleus basalis (Gasbarri et al., 1999). A 
lesion of the cholinergic basal nucleus decreases the cortical ACh level and $5-\mathrm{HT}_{2 \mathrm{~A}}$ receptor binding in layer IV of the cortex (Quirion et al., 1985). Furthermore, 5- $\mathrm{HT}_{2 \mathrm{~A}}$ and/or 5- $\mathrm{HT}_{3}$ receptors are located on cholinergic terminals in the cortex so that serotonergic neurons as well as cholinergic neurons can regulate the cortical function (Maura et al., 1992; Crespi et al., 1997; Giovannini et al., 1998; Dringenberg and Zalan, 1999). Our current data indicate that the cholinergic augmentation of the BF shift is modulated by serotonergic neurons, which can augment or reduce the BF shift or even reverse the direction of the BF shift, and that both the serotonergic and cholinergic systems play an important role in cortical plasticity according to behavioral demands.

\section{References}

Aghajanian GK, Marek GJ (1997) Serotonin induces excitatory postsynaptic potentials in apical dendrites of neocortical pyramidal cells. Neuropharmacology 36:589-599.

Aghajanian GK, Marek GJ (2000) Serotonin model of schizophrenia: emerging role of glutamate mechanisms. Brain Res Brain Res Rev 31:31302-31312.

Araneda R, Andrade R (1991) 5-Hydroxytryptamine2 and 5-hydroxytryptamine 1 A receptors mediate opposing responses on membrane excitability in rat association cortex. Neuroscience 40:399-412.

Barnes JM, Barnes NM, Costall B, Naylor RJ, Tyers MB (1989) 5-HT3 receptors mediate inhibition of acetylcholine release in cortical tissue. Nature 338:762-763.

Barnes NM, Sharp T (1999) A review of central 5-HT receptors and their function. Neuropharmacology 38:1083-1152.

Berntson GG, Tuber DS, Ronca AE, Bachman DS (1983) The decerebrate human: associative learning. Exp Neurol 81:77-88.

Castilho VM, Brandao ML (2001) Conditioned antinociception and freezing using electrical stimulation of the dorsal periaqueductal gray or inferior colliculus as unconditioned stimulus are differentially regulated by 5-HT2A receptors in rats. Psychopharmacology (Berl) 155:154-162.

Chen A, Hough CJ, Li H (2003) Serotonin type II receptor activation facilitates synaptic plasticity via $\mathrm{N}$-methyl-D-aspartate-mediated mechanism in the rat basolateral amygdala. Neuroscience 119:53-63.

Crespi D, Gobbi M, Mennini T (1997) 5-HT3 serotonin hetero-receptors inhibit $[3 \mathrm{H}]$ acethylcholine release in rat cortical synaptosomes. Pharmacol Res 35:351-354.

Davies SJ, Hood SD, Argyropoulos SV, Morris K, Bell C, Witchel HJ, Jackson PR, Nutt DJ, Potokar JP (2006) Depleting serotonin enhances both cardiovascular and psychological stress reactivity in recovered patients with anxiety disorders. J Clin Psychopharmacol 26:414-418.

Dear SP, Fritz J, Haresign T, Ferragamo M, Simmons JA (1993) Tonotopic and functional organization in the auditory cortex of the big brown bat, Eptesicus fuscus. J Neurophysiol 70:1988-2009.

DeFelipe J, Hendry SH, Hashikawa T, Jones EG (1991) Synaptic relationships of serotonin-immunoreactive terminal baskets on GABA neurons in the cat auditory cortex. Cereb Cortex 1:117-133.

DiCara LV, Braun JJ, Pappas BA (1970) Classical conditioning and instrumental learning of cardiac and gastrointestinal responses following removal of neocortex in the rat. J Comp Physiol Psychol 73:208-216.

Dringenberg HC, Zalan RM (1999) Serotonin-dependent maintenance of spatial performance and electroencephalography activation after cholinergic blockade: effects of serotonergic receptor antagonists. Brain Res 837:242-253.

Dunn AJ (1988) Changes in plasma and brain tryptophan and brain serotonin and 5-hydroxyindoleacetic acid after footshock stress. Life Sci 42:1847-1853.

Eison AS, Eison MS (1994) Serotonergic mechanisms in anxiety. Prog Neuropsychopharmacol Biol Psychiatry 18:47-62.

Engert F, Bonhoeffer T (1999) Dendritic spine changes associated with hippocampal long-term synaptic plasticity. Nature 399:66-70.

Gao E, Suga N (2000) Experience-dependent plasticity in the auditory cortex and the inferior colliculus of bats: Role of the corticofugal system. Proc Natl Acad Sci USA 97:8081-8086.

Garnovskaya MN, Nebigil CG, Arthur JM (1995) Spurney RF, Raymond JR. 5-Hydroxytryptamine2A receptors expressed in rat renal mesangial cells inhibit cyclic AMP accumulation. Mol Pharmacol 48:230-237.
Gasbarri A, Sulli A, Pacitti C, McGaugh JL (1999) Serotonergic input to cholinergic neurons in the substantia innominata and nucleus basalis magnocellularis in the rat. Neuroscience 91:1129-1142.

Giovannini MG, Ceccarelli I, Molinari B, Cecchi M, Goldfarb J, Blandina P (1998) Serotonergic modulation of acetylcholine release from cortex of freely moving rats. J Pharmacol Exp Ther 285:1219-1225.

Glennon RA., Dukat M, Westkaemper RB (2000) Serotonin receptor subtypes and ligands. Neuropsychopharmacology: The Fourth Generation of Progress. Retrieved April 6, 2004, from http://www.acnp.org/G4/ GN401000039/.

Gu Q (2002) Neuromodulatory transmitter systems in the cortex and their role in cortical plasticity. Neuroscience 111:815-835.

Harvey JA (2003) Role of the serotonin 5-HT (2A) receptor in learning. Learn Mem 10:355-362.

Harvey JA, Quinn JL, Liu R, Aloyo VJ, Romano AG (2004) Selective remodeling of rabbit frontal cortex: relationship between 5-HT2A receptor density and associative learning. Psychopharmacology (Berl) 172:435-442.

Hasuo H, Matsuoka T, Akasu T (2002) Activation of presynaptic 5-hydroxytryptamine $2 \mathrm{~A}$ receptors facilitates excitatory synaptic transmission via protein kinase $\mathrm{C}$ in the dorsolateral septal nucleus. J Neurosci 22:7509-7517.

Hurley LM, Thompson AM, Pollak GD (2002) Serotonin in the inferior colliculus. Hear Res 168:1-11.

Inoue T, Koyama T, Yamashita I (1993) Effect of conditioned fear stress on serotonin metabolism in the rat brain. Pharmacol Biochem Behav 44:371-374.

Inoue T, Tsuchiya K, Koyama T (1994) Regional changes in dopamine and serotonin activation with various intensity of physical and psychological stress in the rat brain. Pharmacol Biochem Behav 49:911-920.

Irvine DR, Rajan R (1996) Injury- and use-related plasticity in the primary sensory cortex of adult mammals: possible relationship to perceptual learning. Clin Exp Pharmacol Physiol 23:939-947.

Jacobs BL, Azmitia EC (1992) Structure and function of the brain serotonin system. Physiol Rev 72:165-229.

Jakab RL, Goldman-Rakic PS (2000) Segregation of serotonin 5-HT2A and 5-HT3 receptors in inhibitory circuits of the primate cerebral cortex. J Comp Neurol 417:337-348.

Ji W, Suga N (2003) Development of reorganization of the auditory cortex caused by fear conditioning: effect of atropine. J Neurophysiol 90:1904-1909.

Ji W, Gao E, Suga N (2001) Effect of acetylcholine and atropine on plasticity of central auditory neurons caused by conditioning in bats. J Neurophy $86: 211-225$.

Kandel ER (2000) Nerve cell and behavior. In: Principles of neural science, 4/e (Kandel ER, Schwartz JH, Jessell TM, eds), pp 25. New York: McGraw-Hill.

Lambe EK, Goldman-Rakic PS, Aghajanian GK (2000) Serotonin induces EPSCs preferentially in layer $\mathrm{V}$ pyramidal neurons of the frontal cortex in the rat. Cereb Cortex 10:974-980.

LeDoux JE, Sakaguchi A, Reis DJ (1984) Subcortical efferent projections of the medial geniculate nucleus mediate emotional responses conditioned to acoustic stimuli. J Neurosci 4:683-698.

Liang X, Arvanov VL, Wang RY (1998) Inhibition of NMDA-receptor mediated response in the rat medial prefrontal cortical pyramidal cells by the 5-HT3 receptor agonist SR 57227A and 5-HT: intracellular studies. Synapse 29:257-268.

Ma X, Suga N (2004) Lateral inhibition for center-surround reorganization of the frequency map of bat auditory cortex. J Neurophysiol 92:3192-3199.

Maletic-Savatic M, Malinow R, Svoboda K (1999) Rapid dendritic morphogenesis in CA1 hippocampal dendrites induced by synaptic activity. Science 283:1923-1927.

Malyszko J, Urano T, Yan D, Serizawa K, Kozima Y, Takada Y, Takada A (1994) Foot shock-induced changes in blood and brain serotonin and related substances in rats. Jpn J Physiol 44:35-47.

Maura G, Andrioli GC, Cavazzani P, Raiteri M (1992) 5-Hydroxytryptamine3 receptors sited on cholinergic axon terminals of human cerebral cortex mediate inhibition of acetylcholine release. J Neurochem 58:2334-2337.

Meneses A (1999) 5-HT system and cognition. Neurosci Biobehav Rev 23:1111-1125.

Marek GJ, Wright RA, Gewirtz JC, Schoepp DD (2001) A major role for 
thalamocortical afferents in serotonergic hallucinogen receptor function in the rat neocortex. Neuroscience 105:379-392.

Nair SG, Gudelsky GA (2004) Activation of 5-HT2 receptors enhances the release of acetylcholine in the prefrontal cortex and hippocampus of the rat. Synapse 53:202-207.

Ohl FW, Scheich H (2005) Learning-induced plasticity in animal and human auditory cortex. Curr Opin Neurobiol 15:470-477.

Polley DB, Steinberg EE, Merzenich MM (2006) Perceptual learning directs auditory cortical map reorganization through top-down influences. J Neurosci 26:4970-4982.

Puig MV, Santana N, Celada P, Mengod G, Artigas F (2004) In vivo excitation of GABA interneurons in the medial prefrontal cortex through 5-HT3 receptors. Cereb Cortex 14:1365-1375.

Quirion R, Richard J, Dam TV (1985) Evidence for the existence of serotonin type- 2 receptors on cholinergic terminals in rat cortex. Brain Res 333:345-349.

Rasmusson DD (2000) The role of acetylcholine in cortical synaptic plasticity. Behav Brain Res 115:205-218.

Roerig B, Katz LC (1997) Modulation of intrinsic circuits by serotonin $5-\mathrm{HT}_{3}$ receptors in developing ferret visual cortex. J Neurosci 17:8324-8338.

Romano AG, Quinn JL, Liu R, Dave KD, Schwab D, Alexander G, Aloyo VJ, Harvey JA (2006) Effect of serotonin depletion on 5-HT2A-mediated learning in the rabbit: evidence for constitutive activity of the 5-HT2A receptor in vivo. Psychopharmacology (Berl) 184:173-181.

Stark H, Scheich H (1997) Dopaminergic and serotonergic neurotransmission systems are differentially involved in auditory cortex learning: a longterm microdialysis study of metabolites. J Neurochem 68:691-697.
Stutzmann GE, LeDoux JE (1999) GABAergic antagonists block the inhibitory effects of serotonin in the lateral amygdala: a mechanism for modulation of sensory inputs related to fear conditioning. J Neurosci 19:RC8:1-4.

Suga N, MaX (2003) Multiparametric corticofugal modulation and plasticity in the auditory system. Nat Rev Neurosci 4:783-794.

Waterhouse BD, Moises HC, Woodward DJ (1986) Interaction of serotonin with somatosensory cortical neuronal responses to afferent synaptic inputs and putative neurotransmitters. Brain Res Bull 17:507-518.

Weisstaub NV, Zhou M, Lira A, Lambe E, Gonzalez-Maeso J, Hornung JP, Sibille E, Underwood M, Itohara S, Dauer WT, Ansorge MS, Morelli E, Mann JJ, Toth M, Aghajanian G, Sealfon SC, Hen R, Gingrich JA (2006) Cortical 5-HT2A receptor signaling modulates anxiety-like behaviors in mice. Science 313:536-540.

Williams GV, Rao SG, Goldman-Rakic PS (2002) The physiological role of $5-\mathrm{HT}_{2 \mathrm{~A}}$ receptors in working memory. J Neurosci 22:2843-2854.

Xiao Z, Suga N (2002) Reorganization of the cochleotopic map in the bat's auditory system by inhibition. Proc Natl Acad Sci USA 99:15743-15748.

Yan J, Suga N (1999) Corticofugal amplification of facilitative auditory responses of subcortical combination-sensitive neurons in the mustached bat. J Neurophysiol 8:817-824.

Zhang Y, Suga N (1997) Corticofugal amplification of subcortical responses to single tone stimuli in the mustached bat. J Neurophysiol 78:3489-3492.

Zhou FM, Hablitz JJ (1999) Activation of serotonin receptors modulates synaptic transmission in rat cerebral cortex. J Neurophysiol 82:29892999. 